\title{
Research on Positive Psychology of College Students' Mental Health Education
}

\author{
Fuhong Li \\ Department of psychology, Weifang Medical University, Weifang, Shandong 261053, China \\ Email: lfhpsy@163.com
}

Keywords: positive psychology; mental health education; happiness index

\begin{abstract}
Positive psychology is the emerging psychology of contemporary psychology, advocating researches on the positive quality of human beings, including positive emotional experience, positive personality traits and positive social environment. The mental health education of college students has become an important subject of psychological research in our country. Therefore, in order to further improve the mental health education of college students, we should introduce the concept of positive psychology into the mental health education of college students in order to improve the positive psychological quality of college students and improve the psychological quality of college students.
\end{abstract}

\section{Introduction}

Since 1980s, the development of mental health education in colleges and universities has been developed. More and more scholars have realized the importance of mental health education in colleges and universities. Some colleges and universities have put mental health education into school moral education and set up mental health education and psychological counseling. And the policy is also be taken seriously by the government. Moreover, psychological education is a new cause of psychology, and it aims to achieve the meaning and value of psychology, and to cultivate and improve the personality and people's quality of life. At present, most schools and teachers are still more focused on the prevention of psychological education, mainly on solving the psychological barriers of the existence of a small number of students, while the development needs of most students are ignored. At the same time, the positive psychology is a science that studies how to promote the development of individuals and society to help people live a happy life.So from the theory of positive psychology, studying the psychological health education of college students is in line with the development trend of mental health education.

\section{The Basic theory of Positive Psychology}

\section{The definition and health conception of positive psychology}

Psychology has become an independent discipline since it has three missions: the treatment of human mental and mental illness, to help ordinary people live more full of happiness and to find and cultivate people with extraordinary talent. Moreover, positive psychology refers to the study of factors that are positive in human behavior and are emotionally satisfied. Positive psychology is fundamentally a science that studies the positive qualities and development potential of people. It is committed to the conditions that help individuals and groups, as well as to optimize the process of institutional research. As Kennon M.Sheldon and Laura king said: "Positive psychology is a science that focuses on the positive qualities of human development potential and virtue“ and its emergence and development is inseparable from the psychologist Seligman's advocacy. Seligman said: "Contemporary psychology is in a new historical turning point, and psychologists play a very important role and new mission[1, 2].

Thus, the positive psychology of mental health concept mainly includes the following aspects. The first is the concept of positive. Positive psychology is committed to the positive quality of 
human beings, which is both a great respect and praise for human nature, and at the same time a greater understanding of human society. In the traditional mainstream psychology model, people always pay too much attention to possible or the appeared psychological problems. In the rich material world today, the human itself did not feel happier than before. It has been proved that making up for the problem afterwards can not help to solve the problem. Therefore, positive psychology focuses on the "positive", and advocates with a positive vision and ideas to face the human itself and society. Second is the concept of happiness. Happiness index is an important basis for measuring people's quality of life in recent years. Positive psychology on the positive emotions of the study, the focus is on the subjective people's research, and therefore we focus on studying and exploring psychological problems from the positive level. The subjective happiness index is an important basis for mental health status. The goal of psychological health is to promote individual subjective well-being. Third is the concept of prevention. Positive psychology is not only concerned with the negative aspects of psychological problems, but also concerns more about the excavation of individual potentia through the individual's own power to prevent and treat the relevant issues. In the choice of individual intervention, we advocate to improve the individual's positive quality and positive force to overcome the problems. Positive psychotherapy is the ability to intervene human or behavioral problems by enhancing the positive force or positive qualities of people[3].

\section{The main ideas of positive psychology}

Positive psychology helps to achieve the balance of values in psychology. Positive psychology should not only study the loss, defects and injuries, and should deal more with potential, strength and virtue of human beings. It should emphasize that the psychological return of the basic value should be balanced, so positive psychology is a return to the value of contemporary psychological research[4]. Positive psychology fully embodies the people-oriented thinking, and promotes positive theory of human nature, it advocates the potential of people to fully play and live happily. It sets the cultivation of people's positive quality as the fundamental goal of social science research, so that its goals and human goals are highly consistent to realize the harmony between people and society.

Table 1 elaborates the difference of positive psychology and the traditional psychology. Compared to trantional psychology, positive psychology emphasizes the study of each person's positive strength. Positive psychology mainly focusing the following three levels to study the positive forces, namely the subjective level, the individual level and the collective level. The three levels focuse on the positive aspects of optimism, confidence and hope in the future and studies the positive characteristics of personality and positive social systems, which are conducive to nurture and develop people's positive qualities. Positive psychology advocates a positive explanation of the problems that individuals and societies owned. First of all, it explores the primary cause of the problem in many ways, and then to get a positive experience from the problem itself.

Table 1 The difference of positive psychology and the traditional psychology

\begin{tabular}{|c|c|c|}
\hline & Traditional Psychology & Positive Psychology \\
\hline Points of focus & Solve and reduce problems & positive balance \\
\hline Main idea & Problem-focused & Integrated-development \\
\hline $\begin{array}{c}\text { Hypothesis for } \\
\text { people }\end{array}$ & Creat problems and passive & Hopeful and Collective \\
\hline Drawbacks & $\begin{array}{c}\text { Ignore human potential and } \\
\text { defensiveness }\end{array}$ & Still in research phase \\
\hline
\end{tabular}

\section{Status of Mental Health Education of College Students in China}

\section{The importance of mental health education}

Mental health education is the maintenance and promotion of human mental health education activities to help and encourage people to establish the desirde mental health. Mental health 
education should know how to achieve this purpose, and thus taking health-friendly behavior. In addition, it should learn how to seek appropriate help to achieve the purpose of protecting and enhancing mental health. School mental health education is based on the theory and technology of psychology as the main basis combined with the school daily education and teaching work according to the students physiological and psychological development characteristics.

\section{The status of mental health education in China}

China's mental health education of college students has been developed for more than 20 years since the eighties of last century, and has also made great achievements. Especially in the past decade, both in research and in practice, we have made a huge achievement in order to alleviate the psychological problems of college students, and also to prevent the occurrence of various unfortunate events made a certain contribution. However, the overall level of mental health of college students has not been significantly improved, some unfortunate events continue to occur in a small number of students. Figure 1 shows the common problems existed in college students. And even more students that we think is mental health have spend a lot of time on the Internet chat and computer games, the mental health education of students has caused the whole society in deeper reflection. According to the literature research, there are the following drawbacks in the current situation of college students' mental health education. The first is that there is an imbalance in the goal of mental health education. At present, the goal of mental health education of college students is to focus on eliminating the target, and to solve the psychological and psychological conflicts of students is the main task. The treatment is rediagnosis and prevention is light. The psychological development and growth of students guide is ignored. The second is that the mental health education is medical. The object of education is confined to a small number of students with psychological disorders and psychological disorders who carry out the prevention of sex education, besides, the development of human education is not enough attention. At present, there are limitations of college students' mental health education objects. The current mental health education is based on the traditional negative psychology theory, and this theory is a continuum of both ends, that is the disease and health status. This theory thinks that eliminating the disease means health. However, the main target of mental health education is only individuals those with emotional distress, behavioral disorders and adaptive difficulties, which reduces the mental health services. However, in fact, in colleges and universities, all students need the guidance of mental health education and to master the basic knowledge of mental health to maintain the basic skills in the daily life..

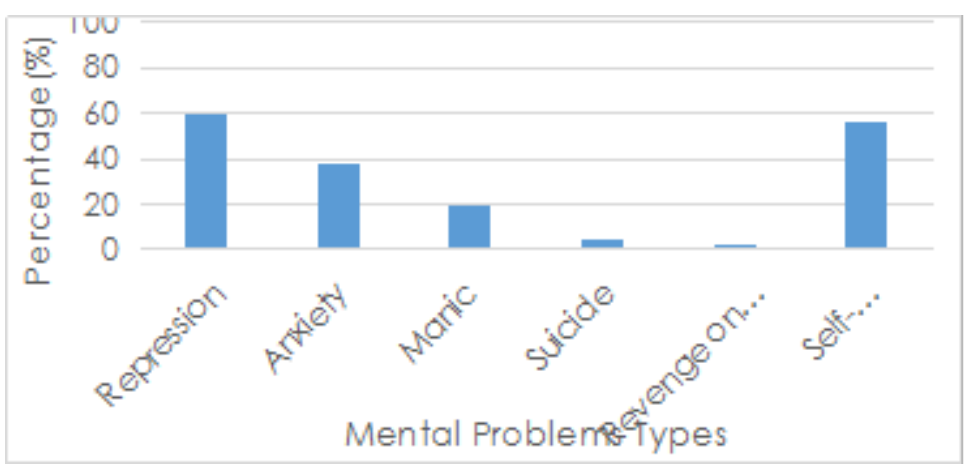

Figure. 1 The existing mental problems of college students.

\section{Strategy of Mental Health Education Based on the Positive Psychology}

\section{The goal of positive psychological health education}

For the educational goals, the main goal of positive mental health education is to enhance the happiness of college students. According to the theory of positive psychology and the characteristics of contemporary college students in our country, the contents of positive psychological health education of college students are as follows: first is to cultivate the positive personality. Second, interpersonal communication is the basic conditions for the healthy growth of 
young people, so training them to identify others and maintaining a positive interpersonal attitude is a major task. Besides, emotional education must guide students to adjust and control self-emotion in the first time. College students should learn to maintain a peaceful state of mind and to avoid the emergence of negative passion. The healthy growth of college students need a good psychological quality which contains two meanings: no mental illness and a positive psychological state. In addition, it is important to cultivate students' frustrating ability.

\section{Effective ways of positive psychology employed in mental health education}

Take into account the positive psychological quality of training and psychological problems to resolve. All teachers should be trained to improve the psychological quality of students to help a small number of students to eliminate psychological problems, as well as taking into account of mental health education in colleges and universities. It is beneficial to the development of psychological education and to play a more active role and significance to the students' psychological problems.

Focus on cultivating students' positive psychological quality. Table 2 shows the various ways for college students to relieve the pressure and negative emotion. In the positive psychology, the psychological health not only includes the absence of mental illness, but also includes the individual has a positive pursuit of a better life and ideals, together with a good social function, good working condition and high efficiency, independent personality, interpersonal relationships, rich spiritual life and so on.

Table 2 The existing mental problems of college students.

\begin{tabular}{|c|c|}
\hline Ways & Percentage(\%) \\
\hline Outdoor activities & 70 \\
\hline Tell friends or teachers & 67 \\
\hline Self-regulation & 50 \\
\hline Books or music & 30 \\
\hline Delicious food & 70 \\
\hline
\end{tabular}

Establish a positive and perfect school mental health education system. In school, mental health education and other work is not opposed or completely divided, the relationship between them is an organic whole. The school, family and social mental health education factors should be reintegrated to build a positive, perfect and unified mental health education system. Thus the greatest effect of mental health education will be established.

\section{Summary}

In summary, the starting point of positive psychology is to explore mental health education from a positive point, and positive psychology education has become a new mainstream of mental health education. Mental health education model has been deeply reformed, and all of this helps to expand a new horizon for positive psychological concepts in college mental health education. the effectiveness of college students mental health education can be effectively improved with the help of a new positive psychological concept integrated in the mental health education in colleges and universities.

\section{References}

[1] Sheldon K.M.,King L.Why Positive Psychology IsNecessary[J]. American Psychologist, 2001(3):56- 67.

[2] Seligman E.P. Building Human Strength: Psychologys Forgotten Mission[J].APAmonitor, 1988(1):12-19.

[3] Seligman M.E.P,Csikzentmihalyi M.Positive Psychology:An Introduction[J].American Psychologist,2000(1):5- 14. 
[4] Bolier L., Haverman M., Westerhof G.J., et al. Positive psychology interventions: a meta-analysis of randomized controlled studies[J]. BMC public health, 2013, 13(1): 119. 